\title{
Statin prescribing in Australia: socioeconomic and sex differences
}

\author{
A cross-sectional study
}

\author{
Nigel P Stocks, Philip Ryan, Heather McElroy and James Allan
}

\begin{abstract}
CORONARY HEART DISEASE (CHD) is a major cause of morbidity and mortality in Australia. ${ }^{1}$ Secondary and primary prevention are acknowledged as appropriate strategies for reducing morbidity and mortality, with guidelines focusing on the major risk factors of age, smoking, high blood pressure, cholesterol levels, family history and diabetes. $^{2}$ Absolute rather than relative risk is now used to determine who might benefit most from treatment. ${ }^{3}$ However, application of risk-factor tables by general practitioners is problematic, ${ }^{4,5}$ and
\end{abstract} it is thought that many individuals with, or at risk of, CHD are currently not receiving adequate treatment. ${ }^{6,7}$ Management of hyperlipidaemia is of particular concern, because of the high cost of statins to the Pharmaceutical Benefits Scheme (PBS) - \$806 million from December 2002 to November $2003 .{ }^{8}$

It is well known that morbidity and mortality from heart disease is greatest in lower socioeconomic groups. ${ }^{1}$ Furthermore, it is thought that women, at least for secondary prevention of CHD, are less likely than men to receive treatment. ${ }^{9}$ It is not known if there is differential prescribing of statins in Australia. If there is, this might be evidence of the inverse care law, ${ }^{10}$ and might have

\section{METHODS}

\section{ABSTRACT}

Objective: To assess if there are any differences in statin prescribing across Australia by socioeconomic status or sex and to relate prescribing rates to coronary heart disease (CHD) mortality rates.

Design: Cross-sectional study using data on statin prescribing by age, sex and patient postcode for the period May to December 2002.

Setting and participants: The Australian population, stratified by sex and quintile of Index of Relative Socio-Economic Disadvantage (IRSD).

Main outcome measures: Age-standardised rates of statin scripts per 1000 population per month for each sex and IRSD quintile.

Results: 9.1 million prescriptions for statins were supplied between May and December 2002, for a total cost of $\$ 570$ million. The age-standardised rates for statin prescribing in women varied from $56.9(95 \% \mathrm{Cl}, 56.6-57.2)$ scripts per 1000 population per month in the most disadvantaged socioeconomic quintile through 53.4 (95\% Cl, 53.0-53.7), 50.3 (95\% Cl, 50.0-50.6), 48.4 (95\% Cl, 48.1-48.7) to 46.3 $(95 \% \mathrm{Cl}, 46.0-46.6)$ in the least disadvantaged quintile. For men the figures were $52.6(95 \% \mathrm{Cl}, 52.3-52.9), 50.9(95 \% \mathrm{Cl}, 50.6-51.2), 48.8$ (95\% Cl, 48.6-49.1), $47.7(95 \% \mathrm{Cl}, 47.4-47.9)$, and $51.9(95 \% \mathrm{Cl}, 51.6-52.2)$. There was a significant linear association between statin prescribing and CHD mortality by quintile of socioeconomic disadvantage in women (weighted least squares slope, $0.380 ; 95 \% \mathrm{Cl}, 0.366$ to 0.395 ; $P<0.0001$ ), but not in men (slope, $-0.002 ; 95 \% \mathrm{Cl},-0.010$ to $0.006 ; P=0.65$ ).

Conclusions: Our results suggest that in men there is either overprescribing of statins in the highest socioeconomic quintile or underprescribing in the lowest. Furthermore, contrary to expectation, women - relative to men - are prescribed statins at higher rates at lower levels of risk (using CHD deaths as a proxy measure of risk).

MJA 2004; 180: 229-231 implications for the PBS budget.

As part of a cardiovascular risk assessment project in general practice, we sought to identify if statin prescribing varies by socioeconomic status in Australia and if there are any differences in rates of prescribing for men and women.

The Australian Department of Health and Ageing provided data about statin

prescriptions subsidised through the PBS and Repatriation Pharmaceutical Benefits Scheme. Because the cheapest statin is $\$ 28.99$, which is above the patient copayment fee ( $\$ 22.40$ for Australians in general and $\$ 3.60$ for concession card holders at February 2002), we expect information on most statins prescribed in Australia to be available.

Data provided by the Department of Health and Ageing included item num-

\footnotetext{
Department of General Practice, University of Adelaide, Adelaide, SA.

Nigel P Stocks, MD, Senior Lecturer; Heather McElroy, DipStats, Lecturer.

Department of Public Health, University of Adelaide, Adelaide, SA.

Philip Ryan, MB BS, Associate Professor.

Hills Medical Service, Adelaide, SA.

James Allan, MB BS, General Practitioner.

Reprints will not be available from the authors. Correspondence: Dr NP Stocks, Department of General

Practice, University of Adelaide, Adelaide, SA 5005. nigel.stocks@adelaide.edu.au
}

bers for atorvastatin, fluvastatin, pravastatin and simvastatin. Data by age, postcode and sex were only available for May to December 2002. The number of scripts and associated costs in this 8month period were divided by eight to give average monthly estimates.

The Socio-economic Indexes for Areas (SEIFA) was used to characterise the socioeconomic quintile of each postcode in Australia, using the Index of Relative Socio-economic Disadvantage (IRSD). ${ }^{11}$ The index is based on such factors as percentage of dwellings being rented, percentage of persons unemployed, in relatively unskilled occupations, lacking fluency in English, Aboriginal or Torres Strait Islanders, and relatively low educational attainment. The scores are based on questions asked in the 1996 census, and are 
provided at the postcode level. Data for 1996 were the most recent available at the time of writing.

Each statin script was assigned to a socioeconomic quintile based on postcode. Direct age standardisation was used to estimate the rate of statin scripts per 1000 population in each IRSD quintile for each sex separately, as the burden of cardiovascular disease varies substantially by sex. The 1991 Australian population by age group $(<25,25-$ 34, 35-44, 45-54, 55-64, 65-74, and $\geqslant 75$ years) and sex was used as the standard population. $^{12}$

We used weighted linear regression models for each sex to examine the relation between statin prescribing rates for each IRSD quintile and the corresponding mortality rates from CHD. Mortality rates were based on deaths in 1997, standardised to the 1991 Australian population (as these were the only data available by socioeconomic quintile). ${ }^{13}$ The regression weights were the inverses of the variances of the prescribing rates in each quintile.

All analyses were performed using SAS. ${ }^{14}$

\section{RESULTS}

There were 9.1 million prescriptions filled for statins between May and December 2002. The government subsidy for these was $\$ 506$ million, and the patient contribution $\$ 64$ million (total cost, $\$ 570$ million). Most of the prescriptions (94.6\%) were written by GPs rather than Other Medical Providers. Because of missing data, $2.7 \%$ of scripts were removed from the analysis.

Age-specific rates (scripts per 1000 population per month) showed substantial variation: $25-34$ years, $2.0 ; 35-44$ years, $13.1 ; 45-54$ years, 55.4; 55-64 years, 156.3 ; 65-74 years, 271.7; and $\geqslant 75$ years, 230.4 . For all ages, the rate was 56.8 scripts per 1000 population per month. Age-standardised rates by quintile of socioeconomic disadvantage for each sex are shown in Box 1. Exami-

\begin{tabular}{|c|c|c|}
\hline \multicolumn{3}{|c|}{$\begin{array}{l}\text { 1: Age-adjusted rates of statin } \\
\text { prescribing }\end{array}$} \\
\hline \multicolumn{2}{|c|}{$\begin{array}{l}\text { Socioeconomic } \\
\text { quintile* }\end{array}$} & \multirow{2}{*}{$\begin{array}{l}\text { Scripts per } \mathbf{1 0 0 0} \text { popula- } \\
\text { tion per month (95\% Cl) } \\
56.90(56.58-57.23)\end{array}$} \\
\hline Women & 1 & \\
\hline & 2 & $53.36(53.04-53.68)$ \\
\hline & 3 & $50.31(50.01-50.62)$ \\
\hline & 4 & $48.37(48.06-48.68)$ \\
\hline & 5 & $46.30(46.04-46.56)$ \\
\hline \multirow[t]{5}{*}{ Men } & 1 & $52.63(52.32-52.94)$ \\
\hline & 2 & 50.89 (50.59-51.20) \\
\hline & 3 & $48.84(48.55-49.14)$ \\
\hline & 4 & $47.68(47.38-47.98)$ \\
\hline & 5 & $51.91(51.64-52.19)$ \\
\hline \multicolumn{3}{|c|}{$\begin{array}{l}\text { *Quintiles of SEIFA index of relative social } \\
\text { disadvantage }(\text { most disadvantaged }=1 \text {; } \\
\text { least disadvantaged }=5)\end{array}$} \\
\hline
\end{tabular}

\section{DISCUSSION}

Our study indicates that men living in the least disadvantaged socioeconomic areas of Australia have higher rates of statin prescribing relative to their cardiovascular risk compared with other men. We cannot be sure whether this difference is due to underprescribing in the lowest socioeconomic quintiles or overprescribing in the highest (with potential costs or savings for the PBS budget), but it appears to be evidence of the inverse care law - that medical care varies inversely with need. ${ }^{10}$

Although our study cannot provide a causal explanation for these findings, we speculate that there may be a range of drivers for statin prescribing. First, patient expectation might fuel demand, with bettereducated and better-remunerated patients having greater expectations about their current and future healthcare and more likely to have adopted messages about men's health. Those with health insurance (more likely to be the least disadvantaged) ${ }^{15}$ are probably more likely to be referred, ${ }^{16}$ be investigated and receive treatment for identified risk factors. Patients in wealthy areas are more likely to have long consultations with their GP. ${ }^{17}$ This extra time could well be spent in preventive activities that would not be available to patients access-

nation of the confidence intervals indicates that each quintile has different rates of statin prescribing.

Box 2 shows that, although deaths from CHD (used here as a proxy for cardiovascular risk) are lowest in the least disadvantaged in both sexes, statin prescribing in men in this group appears to be disproportionately high compared with other socioeconomic quintiles. The regression analysis for men confirmed no significant linear relation between statin prescribing and CHD mortality (slope, $-0.002 ; 95 \%$ CI, -0.010 to $0.006 ; P=0.65)$. In women, there was a significant linear relation (slope, 0.380 ; $95 \% \mathrm{CI}, 0.366$ to $0.395 ; P<0.0001$ ). ing care from GPs predominantly servicing lower socioeconomic areas. Do GPs, who are still predominantly male, middle-aged and middle class, ${ }^{18}$ identify more strongly with their peers in a way that influences their preventive message and prescribing behaviour?

Our study also shows high rates of statin prescribing for women compared with men. Women in the lowest socioeconomic group receive more statin scripts than any other group. Importantly, despite being at much lower risk of death from CHD, women in this group receive more statins than men in similar economic circumstances. This is contrary to evidence from the United 
Kingdom which suggests that women with established CHD are less likely to be prescribed lipid-lowering medication than men. ${ }^{9}$ Again, we can only speculate as to the reasons for these differences. We know that attendance at GPs is greatest among women, including attendance for cardiovascular problems, ${ }^{19}$ so it is possible that the opportunity to discuss primary and secondary prevention with a GP is important. We know that women are more likely to self-report diseases of the circulatory system (including hypertensive disease, $\mathrm{CHD}$ and varicose veins) and diabetes than men, at least in the lowest socioeconomic group. ${ }^{15}$ This might account for some of the difference, although women's rates of smoking are less than rates in men and could balance any increased risk due to diabetes and hypertension.

New lipid management guidelines have been published, ${ }^{20}$ and it has been suggested that previous guidelines in Australia were poor discriminators of absolute CHD risk for primary prevention. ${ }^{21}$ GPs using inappropriate guidelines might explain some of the observed differences, but this would require differential application to men and women across the socioeconomic spectrum. Finally, we do not know if the observed differences are due to the use of statins for primary or secondary prevention.

There are several potential limitations in this study. We described the collection of statins as "prescribing" when, strictly, it is "dispensing", so we have not accounted for scripts that were prescribed but not dispensed, or scripts that were dispensed but not taken. Poor compliance with lipid-lowering drugs has been identified previously in the Australian population; ${ }^{22}$ however, no sex differences in compliance were found, so our results are unlikely to be explained purely by differential levels of compliance. Secondly, we cannot be sure that just because a person lives in an area of socioeconomic advantage or disadvantage that he or she shares the same socioeconomic status as his or her neighbours. However, the SEIFA index is well accepted and any such misclassification would diminish rather than enhance our findings. Finally, we have used several sources of data ranging from 1990 to 2002. The age structure of the Australian population has changed in that time, and cardiovascular morbidity and mortality have fallen, although the evidence suggests any decline has been uniform across socioeconomic groups. ${ }^{23}$ Again, all these limitations affect the size of any difference, not the direction.

Our results suggest that, for men, there is either overprescribing of statins in the least disadvantaged group or underprescribing in the most disadvantaged, with a gradient across quintiles of socioeconomic disadvantage. Furthermore, contrary to expectation, women are prescribed statins at higher rates at lower levels of risk (using CHD deaths as a proxy measure of risk) than men. Although the differences we have identified may seem small, even small differences in prescribing rates can make substantial differences in costs, morbidity and mortality. Further research should be undertaken to explore the reasons behind these differences and initiatives undertaken to reduce healthcare inequalities.

\section{ACKNOWLEDGEMENTS}

This research was funded by a 2002 Royal Australian College of General Practitioners (Pfizer) Cardiovascular Research Grant. It was also supported by the Primary Health Care Research, Evaluation and Development (PHCRED) Program. We wish to thank Professor George Davey-Smith and Dr John Furler, who gave comments on early drafts, and Kristyn Wilson, who assisted with data analysis.

\section{COMPETING INTERESTS}

None identified.

\section{REFERENCES}

1. Bennett S. Socioeconomic inequalities in coronary heart disease and stroke mortality among Australian men, 1979-1993. Int J Epidemiol 1996; 25: 266-275.

2. National Preventive and Community Medicine Committee RACGP. Guidelines for preventive activities in general practice. Aust Fam Physician 2002; 31(S1): 17-28.

3. Jackson R. Guidelines on preventing cardiovascular disease in clinical practice. BMJ 2000; 320: 659-661.

4. Fairhurst K, Huby G. From trial data to practical knowledge: qualitative study of how general practitioners have accessed and used evidence about statin drugs in their management of hypercholesterolaemia. BMJ 1998; 317: 1130-1134.
5. Grover S, Lowensteyn I, Esrey K, et al. Do doctors accurately assess coronary risk in their patients? Preliminary results of the coronary health assessment study. BMJ 1995; 310: 975-978.

6. Taylor R, Chey T, Bauman A, Webster I. Socioeconomic, migrant and geographic differentials in coronary heart disease occurrence in New South Wales. Aust N Z J Public Health 1999; 23: 20-26.

7. Sexton PT, Sexton TH. Excess coronary mortality among Australian men and women living outside the capital city statistical divisions. Med J Aust 2000; 172: $370-374$

8. Health Insurance Commission. Pharmaceutical Benefits Scheme statistical report for items 8213G, 8214H, 8215J, 8521L, 8023G, 8024H, 2833D, 2834E, 8197K, 2013Y, 2011W, 2012X, 8173E, $8313 \mathrm{M}$, by scheme by state, December 2002 to November 2003. Available at: www.hic.gov.au/statistics/dyn_pbs/forms/pbs_tab1.shtml (accessed Jan 2004).

9. Hippisley-Cox J, Pringle M, Crown N, et al. Sex inequalities in ischaemic heart disease in general practice: cross sectional survey. BMJ 2001; 322: 832.

10. Hart JT. The inverse care law. Lancet 1971; 1 : 405-412.

11. Australian Bureau of Statistics. 1996 Census of Population and Housing: Socio-Economic Indexes for Areas [Information paper]. Canberra: ABS, 1998. (ABS Catalogue No. 2039.0.)

12. Australian Bureau of Statistics. Population by age and sex, Australian states and territories. Canberra: ABS, 2003. (ABS Catalogue no. 3201.0.)

13. Australian Institute of Health and Welfare. Heart, stroke and vascular diseases - Australian facts 2001. Cardiovascular Disease Series No. 14. Canberra: AlHW, National Heart Foundation of Australia National Stroke Foundation of Australia, 2001. (AlHW Catalogue No. CVD13.)

14. SAS [computer program]. Version 8.02. Cary, NC: SAS Institute Inc, 1999

15. Australian Bureau of Statistics. National Health Survey: summary of results. Canberra: ABS, 2001. (ABS Catalogue No. 4364.0.)

16. Mclsaac W, Goel V, Naylor D. Socio-economic status and visits to physicians by adults in Ontario, Canada. J Health Serv Res Policy 1997; 2: 94-102.

17. Furler JS, Harris E, Chondros $P$, et al. The inverse care law revisited: impact of disadvantaged location on accessing longer GP consultation times. Med $J$ Aust 2002; 177: 80-83.

18. Commonwealth Department of Health and Aged Care. General practice in Australia: 2000. Canberra: Commonwealth Department of Health and Aged Care, 2000

19. Henderson J, Pan Y, Britt H, et al. Cardiovascular problems and risk behaviours among patients at general practice encounters in Australia 1998-00. General Practice Series No. 9. Canberra: AlHW, 2002. (AlHW Catalogue No. GEP 9.)

20. Barter $P$, Best $P$, Boyden $A$, et al. Lipid management guidelines - 2001. Med J Aust 2001; 175 (Suppl): S61-S84. Available at: www.heartfoundation.com.au/ downloads/lipid_guide_2001.pdf (accessed Jan 2004).

21. Forge BH, Briganti EM. Lipid lowering and coronary heart disease risk: how appropriate are the national guidelines? Med J Aust 2001; 175: 471-475.

22. Simons LA, Levis G, Simons J. Apparent discontinuation rates in patients prescribed lipid-lowering drugs. Med J Aust 1996; 164: 208-211.

23. McElduff $P$, Dobson AJ. Trends in coronary heart disease - has the socio-economic differential changed? Aust N Z J Public Health 2000; 24: 465-473.

(Received 30 May 2003, accepted 18 Dec 2003) 